low. Superior appendages two and a half times as long as wide, nearly as long as ro, directed backward, equal or slightly enlarged apically, dorsal margin one-fifth longer, slightly concave, apex obliquely truncate, angles rounded, distal margin concave or shallowly emarginate. In dorsal view stouter at base, only twice as long as wide, the upper limb tapering to a rounded tip which bears a short, stout tooth on the inner side next the rounded apex; the lower limb projects inward making the two sides of the whole appendage nearly parallel, the inner apical margin truncate. The inferior appendages are three-fifths as long as the superior, stout, tapering to a blunt point, directed caudad, a little incurved. $\subsetneq$ : humeral pale stripe one-third as wide as the dark stripe, a line on second lateral suture, and a short line between it and the humeral stripe. Dorsum of I-IO greenish black, not narrowed, more or less maculate on $10: 3^{-6}$ with interrupted basal ring, 7 and 8 with apical margin yellow.

Abd.: $\delta, 25 ; \varnothing, 26.5$. Hind wing: $\delta$, $16.5 ;$ ㅇ, 18.5 .

I $\delta$, I $q$, Sherborn, Mass., collected by Mr. A. L. Babcock, to whom I am indebted for an opportunity to examine and describe them and who has donated the types to the Hagen collection at Cambridge, Mass., in conjunction with the other types described by me from my own collection in this and the preceding paper̂s.

\section{NOTES ON MOTHS.}

Amphion nessus. - Last year I found young larvae of Amphion nessus on Ampelopsis veitchii, and this year I have found them on Ampelopsis quinquefolia, one specimen being of a clear wine-color, with subdorsal and oblique lines pink edged above with deep claret-color. The granulation was pale yellow, as were the face lines and the edge of the anal plate. The larvae drop from the vine at a very slight shake and are easily found in this way.

"Red-fringed" Actias luna.-In early June Miss Norton sent me eggs of the $A$. luna having deep red fringes on its wings. These eggs hatched twelve days after they were laid, and the larvae differed from any $I$ had seen in having a dark brown lateral band from head to anal shield; a dark brown patch on the dorsum of the third and of the pre-anal segments, with the anal plate blackishbrown. The bristles from the tubercles were black with some white ones. The feet were green with a brown patch on each. At the first moult they came out like normal Luna larvae.

Attacus promethea.-Is this moth rare this year? I have placed on my window-sill nine females, but in no case has a male been attracted. Last year every female which emerged in my box attracted from five to forty males, and some of the females were not even near the open window.

Caroline G. Soule.

Brookline, Mass., Fune 30,1895 .

\section{PROCEEDINGS OF THE CLUB.}

$8 \mathrm{March}, \mathrm{r} 895$. The I86th meeting was held at ${ }_{5} 6$ Brattle St., Mr. S. Henshaw in the chair. Mr. A. G. Mayer was chosen secretary.

Mr. Wr. L. W. Field was elected a member.

Mr. S. H. Scudder read the delayed address of the retiring President, Mr. T. E. Bean, entitled "A comparison of Colias hecla with Colias meadii and Colias elis."

Mr. S. Henshaw asked what the distribution of C. hecla was. Mr. Scudder stated that it was quoted from Greenland, Lapland, Hudson Bay, Bering Straits and Grinnellland and $C$. meadii from Colorado, Arizona, and New Mexico.

A paper by Mr. W. S. Blatchley on winter collecting (see Psyche, vii, 247) was read. Mr. Henshaw stated that he had found between 2-30o species of Coleoptera and a few larvae by sifting leaves during the winter months; the greater number of species thus found were Pselaphidae and Staphylinidae.

Mr. Henshaw exhibited a specimen of Lycaena xerces from San Francisco. This species was erroneously supposed to have been exterminated by the extirpation of its food plant. 

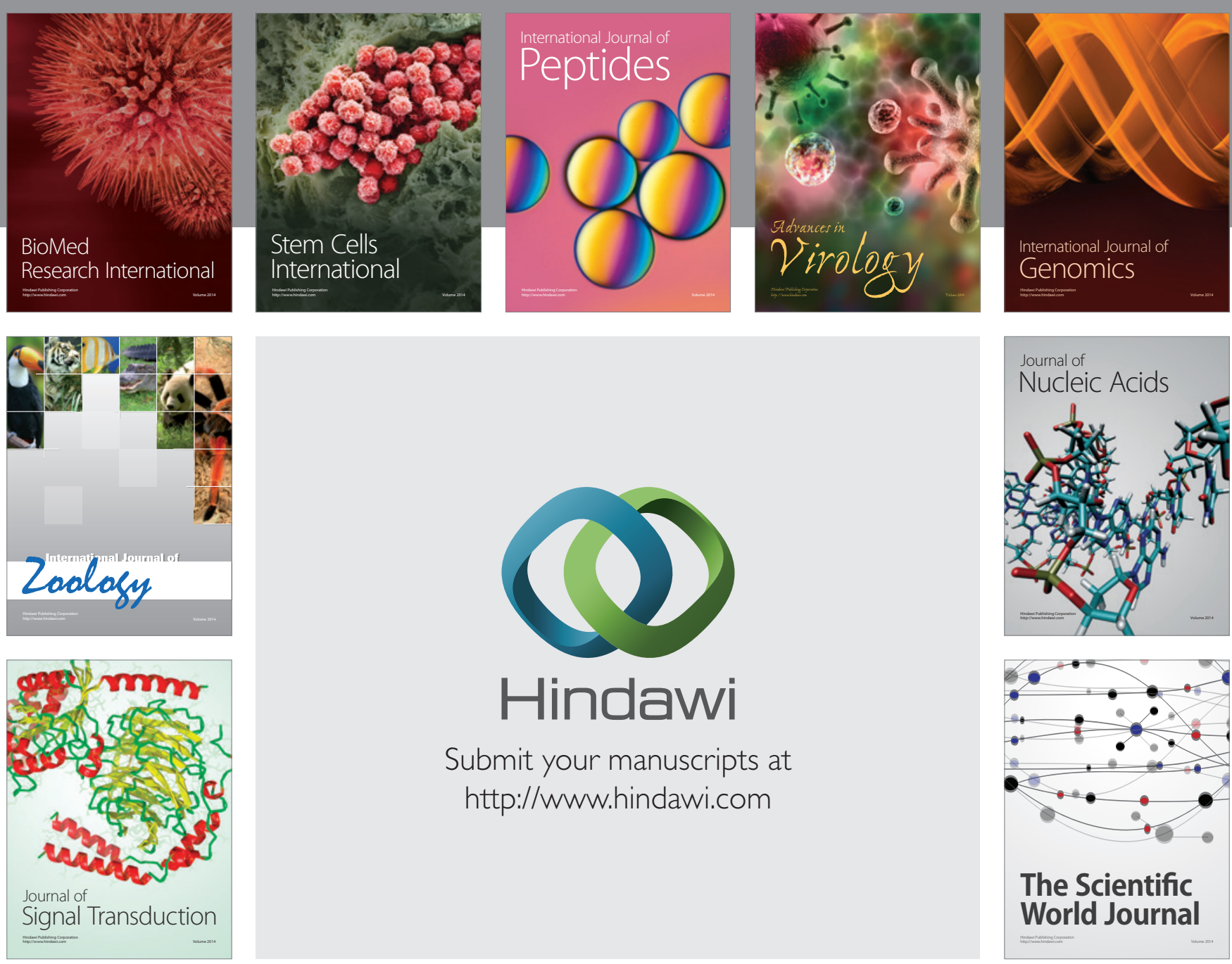

Submit your manuscripts at

http://www.hindawi.com
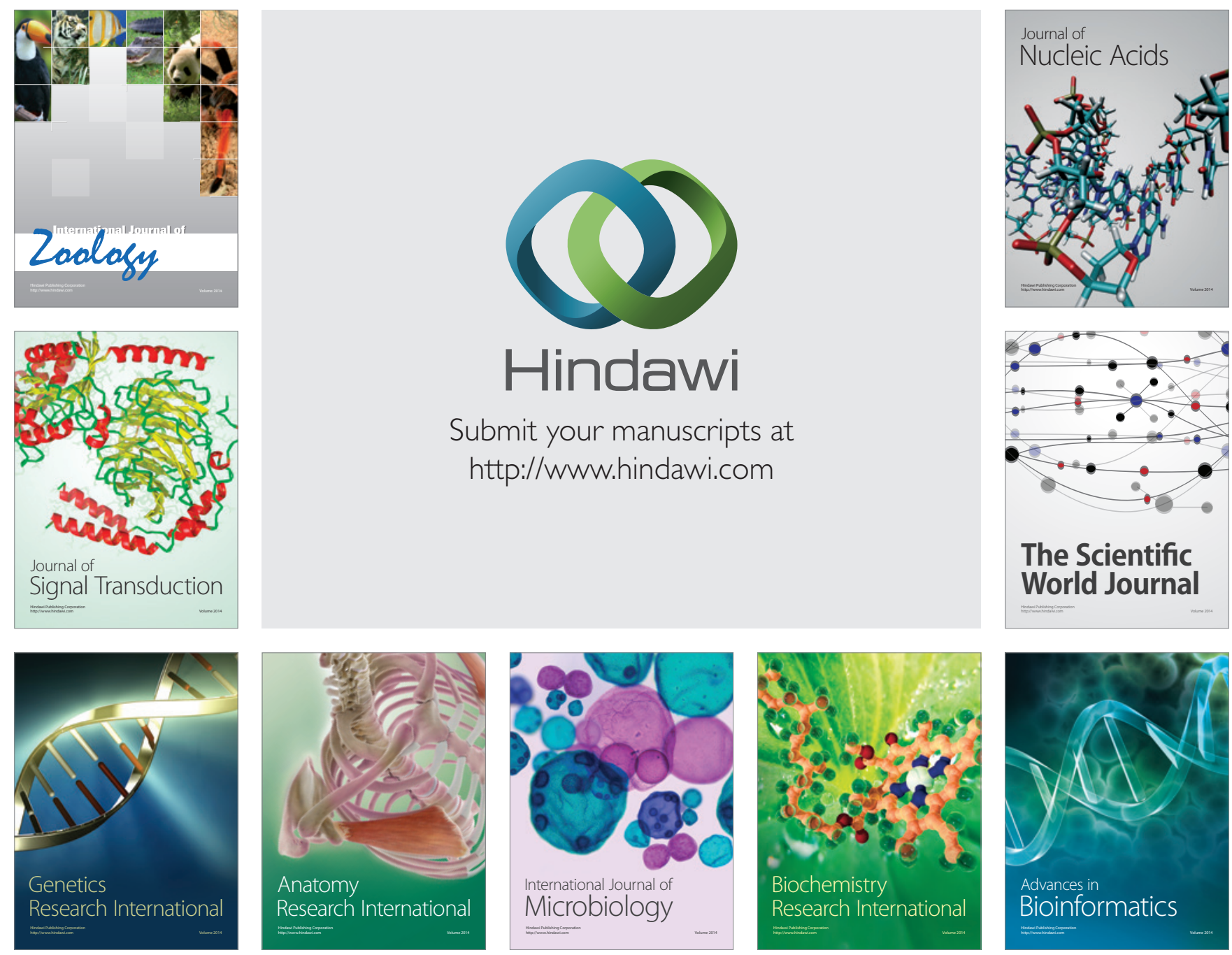

The Scientific World Journal
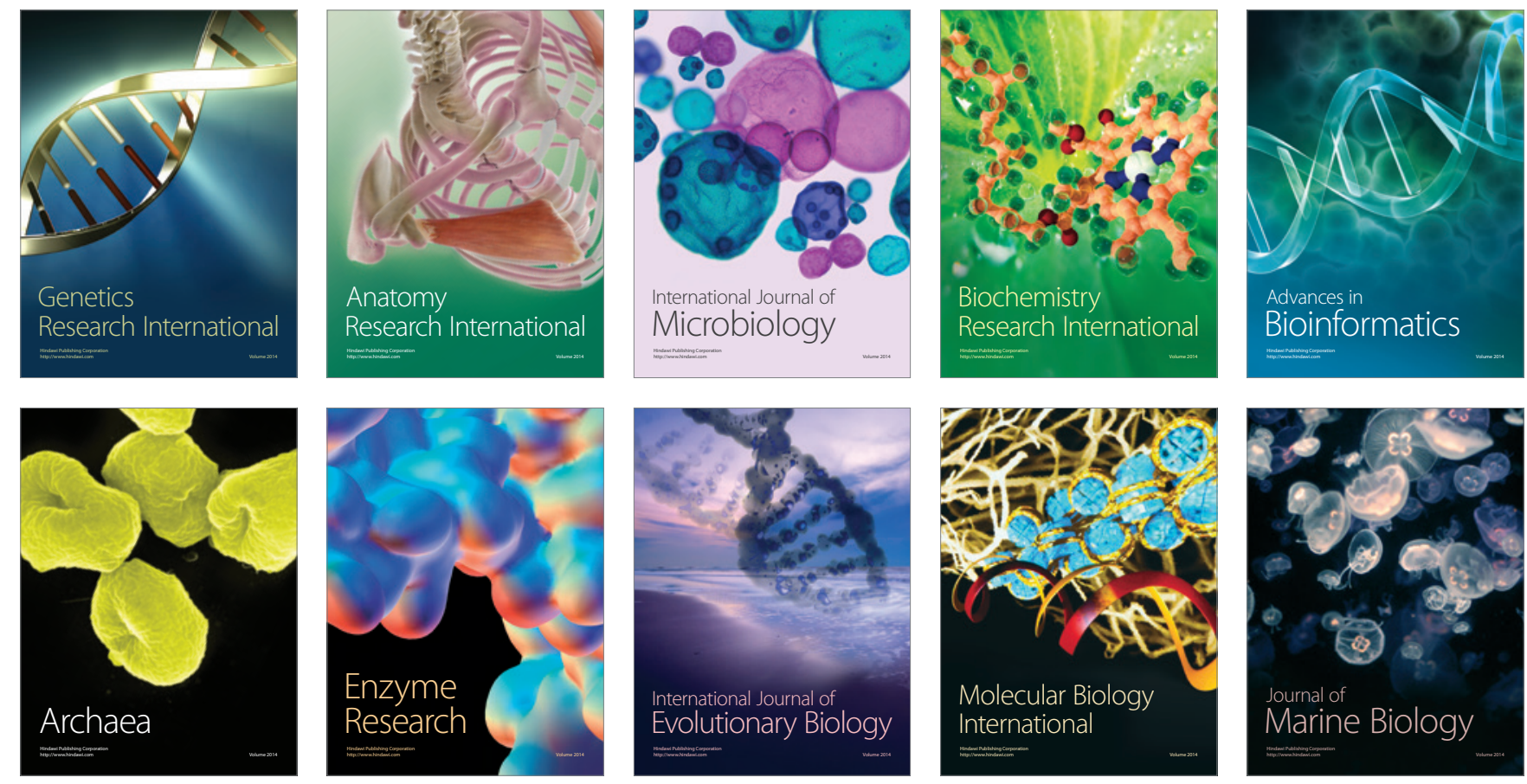